Jurnal Keperawatan Hang Tuah ( Hang Tuah Nursing
Journal)
e-ISSN 0000-0000
https://jom.htp.ac.id/index.php/jkh

\title{
ANALISIS PERSEPSI PERAWAT PELAKSANA TENTANG GAYA KEPEMIMPINAN KEPALA RUANGAN TERHADAP KINERJA PERAWAT
}

\author{
Yoda Triadi ${ }^{1)}$, Raja Fitrina Lestari'2), Bayu Saputra ${ }^{3)}$ \\ Program Studi IImu Keperawatan STIKes Hang Tuah Pekanbaru \\ Korespondensi email : ${ }^{2}$ rajafitrinalestari@htp.ac.id
}

\begin{tabular}{|c|c|}
\hline Histori artikel & Abstrak (Arial 10, dicetak tebal) \\
\hline 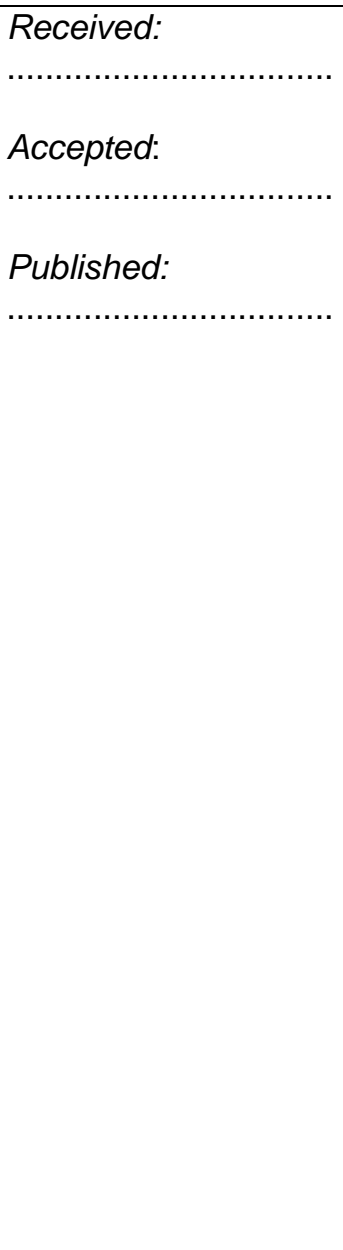 & $\begin{array}{l}\text { Gaya kepemimpinan merupakan perilaku pimpinan terhadap } \\
\text { pengikutnya atau cara yang dipergunakan untuk mempengaruhi } \\
\text { para pengikutnya. Gaya yang diterapkan oleh seorang kepala } \\
\text { ruangan dapat menjadi penilaian tersendiri oleh para perawat } \\
\text { bahkan dapat mempengaruhi kinerja seorang perawat. Penelitian } \\
\text { ini bertujuan untuk mengetahui persepsi perawat pelaksana } \\
\text { tentang gaya kepemimpinan kepala ruangan terhadap kinerja } \\
\text { perawat. Penelitian ini merupakan penelitian kualitatif dengan } \\
\text { desain deskriptif kualitatif. Partisipan utama pada penelitian ini } \\
\text { berjumlah } 8 \text { perawat dan partisipan pendukung berjumlah } 4 \\
\text { perawat yang bekerja diruang rawat inap rumah sakit petala bumi. } \\
\text { Teknik sampling yang digunakan adalah purposive sampling. } \\
\text { Metode pengumpulan data yang digunakan adalah wawancara } \\
\text { mendalam. Data dianalisa dengan menggunakan teknik collaizi. } \\
\text { Penelitian ini mengidentifikasi } 4 \text { tema terkait persepsi perawat } \\
\text { pelaksana tentang gaya kepemimpinan kepala ruangan terhadap } \\
\text { kinerja perawat yaitu, kepemimpinan, gaya kepemimpinan, } \\
\text { supervisi kepala ruangan dan kinerja. Diharapkan dengan adanya } \\
\text { penelitian ini pimpinan rumah sakit dapat menerapkan dan } \\
\text { mempertahankan gaya kepemimpinan yang berdampak positif } \\
\text { untuk meningkatkan kinerja perawat dalam memberikan asuhan }\end{array}$ \\
\hline
\end{tabular}


keperawatan sehingga pelayanan oleh perawat pelaksana lebih maksimal.

Kata kunci: Gaya kepemimpinan, Kinerja perawat

\begin{abstract}
Leadership is an attitude of leader to his adherents or a way to influence them. Attitude which is showed by a theward can be one of assessments by the nurses even it can influence their performance. This research served to find out the perception of the executive nurses about the attitude of theward the performance of the nurses. It was a qualitative research with qualitative descriptive design. The participants main were eight nurses and participants supporters were four nurses who work at petala bumi hospital. The sampling technique was purposive sampling. The data collection method was deeply interview. The data was analyzed by using collaizi technique. It identified four characters related to perception of the nurses about the attitude of theward the performance of nurses. They were leadership, attitude of leader, supervision, and performance. It is expected that the this research leaders hospital can apply and maintain leadership attitude had a positive impact to improve their performance of the nurses in giving nursing care so that the service will be better and more maximal.
\end{abstract}

Keyword: Leadership attitude, Performance of nurses 


\section{PENDAHULUAN}

Rumah Sakit sebagai suatu organisasi perlu meningkatkan mutu pelayanan keperawatannya. Meningkatkan mutu pelayanan keperawatan dibutuhkan tenaga perawat yang profesional. Fungsi manajerial yang menangani pelayanan keperawatan di ruang rawat dikoordinatori oleh kepala ruang rawat. Kepala ruangan adalah seorang tenaga keperawatan yang diberi tanggung jawab dan wewenang dalam mengatur dan mengendalikan kegiatan pelayanan keperawatan di ruang rawat (Kurniadi, 2013).

Menurut Zulfikhar (2016), Kepala ruang sebagai pemimpin perlu melakukan pembinaan atau pengarahan kepada perawat pelaksana dan pengembangan motivasi, inisiatif dan keterampilan agar dapat melaksanakan tugasnya dengan baik.

Keberhasilan kepemimpinan tidak selalu didasarkan pada tinggi rendahnya latar belakang pendidikan, namun lebih dikarenakan karena ada rasa saling menghormati dan komunikasi antara pimpinan dan anak buah (Kuntoro, 2010). Suatu organisasi akan berhasil atau bahkan gagal sebagian besar ditentukan oleh kepemimpinan (Thoha, 2012).

Gaya kepemimpinan yang terdapat dalam setiap organisasi dipandang sebagai suatu proses kunci bagi keberhasilan organisasi. Gaya yang diterapkan oleh seorang kepala ruangan dapat menjadi penilaian tersendiri oleh para perawat dan bahkan dapat mempengaruhi kinerja seorang perawat (Nursalam, 2015).

Hasil survei awal yang dilakukan peneliti kepada 5 partisipan di Rumah Sakit Petala Bumi dengan cara wawancara ditemukan permasalahan mengenai gaya kepemimpinan. 2 partisipan diantaranya merasa tidak nyaman dengan gaya kepemimpinan kepala ruangan. Dengan alasan kurangnya pengarahan dan bimbingan dalam memberikan asuhan keperawatan dikarenakan kepala ruangan tidak selalu berada ditempat, dan terkait mengenai pengambilan keputusan dialihkan kepada perawat pelaksana. sehingga membuat suasana ruangan menjadi tidak nyaman dan menimbulkan tekanan di dalam ruangan. partisipan menyatakan gaya kepemimpinan kepala ruangan itu sangat berpengaruh terhadap kinerja perawat, dengan gaya kepemimpinan yang baik itu akan membuat perawat dan kepala ruangan akan menjadi lebih dekat dan kerjapun menjadi lebih efisien. Berdasarkan fenomena yang terjadi dilapangan maka peneliti tertarik melakukan penelitian "Analisis Persepsi Perawat Pelaksana Tentang Gaya Kepemimpinan Kepala Ruangan Terhadap Kinerja Perawat".

\section{METODOLOGI}

Penelitian ini merupakan penelitian deskriptif kualitatif untuk mengetahui persepsi perawat pelaksana tentang gaya kepemimpinan kepala ruangan terhadap kinerja perawat. Metode 
pengumpulan data yang digunakan adalah wawancara mendalam kepada perawat pelaksana dengan menggunakan pedoman wawancara. Analisa data pada penelitian ini berdasarkan sembilan tahap analisis Collaizi.

\section{HASIL}

Partisipan utama pada penelitian ini berjumlah 8 perawat dan partisipan pendukung berjumlah 4 perawat yang bekerja diruang rawat inap rumah sakit petala bumi.

\begin{tabular}{|c|c|c|c|c|}
\hline \multicolumn{5}{|c|}{$\begin{array}{c}\text { Tabel } 4.1 \\
\text { Data Partisipan utama }\end{array}$} \\
\hline No Partisipan & Jenis Kelamin & Usia & Pendidikan terakhir & $\begin{array}{c}\text { Lama } \\
\text { bekeria }\end{array}$ \\
\hline Partisipan 1 & Perempuan & 30 th & D4 kebidanan & 7 th \\
\hline Partisipan 2 & Perempuan & 53 th & D3 kebidanan & 6 th \\
\hline Partisipan 3 & Perempuan & 30 th & S1 keperawatan, Ners & 7 th \\
\hline Partisipan 4 & Perempuan & 30 th & S1 keperawatan, Ners & 6 th \\
\hline Partisipan 5 & Perempuan & 28 th & S1 keperawatan, Ners & 5 th \\
\hline Partisipan 6 & Perempuan & 31 th & D3 keperawatan & 6 th \\
\hline Partisipan 7 & Perempuan & 29 th & S1 keperawatan, Ners & 5 th \\
\hline Partisipan 8 & Perempuan & 32 th & S1 keperawatan, Ners & 3 th \\
\hline \multicolumn{5}{|c|}{$\begin{array}{c}\text { Tabel } 4.2 \\
\text { Data Partisipan pendukung }\end{array}$} \\
\hline No Partisipan & Jenis Kelamin & Usia & Pendidikan terakhir & $\begin{array}{l}\text { Lama } \\
\text { bekeria }\end{array}$ \\
\hline Partisipan 1 & Perempuan & 28 th & D3 kebidanan & 3 th \\
\hline Partisipan 2 & Perempuan & $28 \mathrm{th}$ & S1 keperawatan, Ners & 4 th \\
\hline Partisipan 3 & Perempuan & 33 th & S1 keperawatan, Ners & 6 th \\
\hline Partisipan 4 & Laki-laki & 30 th & S1 keperawatan, Ners & 5 th \\
\hline
\end{tabular}

Berdasarkan penelitian didapatkan sebanyak 4 tema.

Kepemimpinan

"ya kalo menurut saya yang bisa mengayomi bawahannya. Yang bisa menjadi pimpinan yang baik la untuk anak buahnya. Bisa mengerti satu sama lain, bisa kompromi (pandangan kearah peneliti). (P1)

"bagi saya seorang leader yang bisa memimpin bukan hanya sekedar memimpin sebatas meja setengah biro tapi pemimpin yang bisa mengayomi, pemimpin tu rela berkorban waktu, tenaga dan pikiran, jadi tidak hanya sekedar memerintah atau mendoktrin atau mengultimatum. Harus bisa memanage semuanya itu lah seorang pemimpin (menggerakan tangan sambil menegaskan jawaban)". (P2)

"kepemimpinan itu dia yang mengatur dan dia yang membimbing, mengarahkan bukan dia

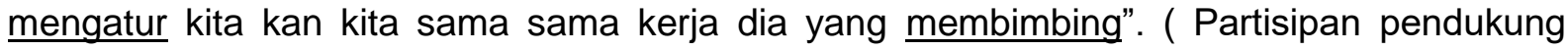
$\mathrm{P} 1, \mathrm{P} 2)$

"kepemimpinan itu memimpin suatu ruangan .kek kek gini kan ruang rawat inap. Merangkul yg lain, Pemimpin nya kayak kepala ruangan . kek demokrasi, otoriter. Kek kek gitu (tersenyum dan pandangan kearah peneliti)". (P3) 
"heee pemimpin he apa gimana ya,kepemimpinan, yang membawahi anggotanya, menggerakan. (sedikit terbata-bata saat menjelaskan)". (P4)

"Cara seorang memimpin gimana bisa membawahi dan mengikuti aturan bisa membawa dan membimbing apalah pokoknya jadi akrab tidak hanya sekedar pimpinan dan bawahan. Tapi balance, karna bekerja gak selalu atasan dan bawahan jadi kek berkeluarga saling keterkaitan jadi gak kaku". (Partisipan pendukung P3,P4)

"kepemimpinan itu harus bertanggung jawab kepada ruangan nya terus mengevaluasi cara kerja perawat nya kan, terus kalau pimpinan yang sekarang ini apa namanya ni bisa di bilang dia bertanggung jawab pokok nya dia eeee kalau ada masalah bisa di atasinya tidak langsung ke bawah, kadang ada karu yang tidak bisa menyelesaikan masalah masalah nya. ia merangkul bisa kerja sama gitu(menjelaskan sambil memegang kotak kecil)"(P5)

"secara umumnya kepemimpinan itu memimpin suatu organisasi yaa aa yang bersifat umum untuk mengatur sagala sesuatu yang ada di organisasi nya (ekspresi wajah tenang saat menjelaskan)". (P6)

"Kepemimpinan istilahnya yang mengatur yang memimpin ruangan yang pertama, staffnya gitu, he merangkul bawahannya ntah kayak ada informasi dari atasankan".(Partisipan pendukung P5,P6)

"Kepemimpinan itu istilah nya sebagai contoh untuk yang dibawah, kalau pemimpin nya bagus bagus juga dibawahnya (pandangan kearah peneliti)".(P7)

"kepemimpinan itu bearti bisa dikatakan dia yang dituakan untuk membimbing kami yang dibawah (menjelaskan sambil memegang pulpen)".(P8)

"metode setiap orang untuk memimpin untuk mengendalikan seluruh aktifitas yang ada diruangan tersebut".

( Partisipan pendukung P7,P8)

Gaya kepemimpinan

"ya yang bisa lah mengertilah sama karyawannya demokrasi dia. Tidak ada satu sisi aja, dia bisa berbaur denga karyawannya, kalo sekarang sih demokrasi (menjelsakan sambil memegang sisi pada jilbab)“.(P1 )

"kalo kepala ruangan kami demokrasi tidak otoriter, Kalo dia demokrasi - ya kan pemimpin sekarang di tuntut untuk demokrasi. Kalo kita otoriter itu tidak bisa Karna kan di era reformasi bawahan pun berhak untuk protes apa yang tidak disukai bawahan (menjelaskan sambil menggerakkan tangan)".(P2 )

"orang nya gak terlalu menekanlah, kan ada karu yang menekan, kalau dia endak, dia selalu melibatkan berarti demokrasi tu ya". 
(partisipan pendukung P1,P2)

"yang sekarang ini Alhamdulillah demokrasi (menggerakan tangan saat berbicara)".(P3 )

"gaya kepemimpinan nya hmmm ada demokratis bisa, selain demokratis apa lagi ya . otoriter kayak nya sih enggak. Demokratis sama laissez faire kayak nya, ya di bilang laissez faire gak juga sih. Lebih ke demokratis (mejelaskan tetapi sedikit kontak mata dengan peneliti)".(P4 )

"disini kalo memutuskan sesuatu pasti berembuk ada dirundingkan dengan anggotanya. Tapi kalo ini mengarah ke demokrasi kan kita juga di libatkan"

(Partisipan pendukung P3,P4)

“ kalau disini demokrasi, kita ada kerja sama kalau misalnya tidak ada kerja sama apa lagi tidak ada komunikasi kan susah kan, apa lagi kalau sendiri sendiri kan, kalau kita apa lagi pasien nya ramai jadi gak bisa ngerjakan sendiri kan (menggerakan tangan )". (P5 )

"aaaa demokrasi ya jugak, karna yakan permintaan dinas di kabulkan, kalau otoriter kan berdasarkan kepala ruangan aja kan (pandangan kearah peneliti)".(P6 )

"ya pemimpinnya suka bertanya dan melibatkan perawat pelaksananya juga,mengarah ke demokrasi dan minta pendapat dari kita juga". (Partisipan pendukung P5,P6)

"kalau selama ini gaya kepemimpinan nya kadang sih secara musyawarah ada individu ada juga, demokrasi yang paling seringlah, di bicarakan di nersstation (menjelaskan sambil memegang sisi jilbab)". (P7 )

"oo demokrasi, soal nya disini semua dibicarakan, termasuk jadwal dinas gitukan harus berdasarkan kesepakatan kita juga (menjelaskan sambil mencatat)". (P8 )

"kalo disini demokrasi karna kita juga terlibat dan dilibatkan".

(Partisipan pendukung P7,P8)

\section{Supervisi kepala ruangan}

"jika ada masalah ya dengan anggota ya dibicarakan tatap muka, tatap mata, dibicarakan apa kendalanya, dimana kendalanya, salah nya dimana,yaaa kalo forum ada juga , kan kita ada rapat ruangan setiap bulannya disitu kita ungkapin apa masalahnya, apa maunya apa solusinya ( menjelaskan sambil menggulung ujung jilbab").(P1)

"ya misalnya ada masalah, tidak tau cara menolong persalinan. Ya di panggil . ada kesalahan dengan pasien ya dia akan panggil akan dijelaskan. Kalo dengan pasien kek gini-gini tidak usah seperti itu. Dan kadang ada juga komplen dengan jadwal. Kek gini kek gini ya tapi dia dengan legowo dia menerima dengan lapang dada, ya namanya manusia tidak da yang sempurna.dia orangnya selalu menerima kok nah itu di cari solusi yang terbaik (menegaskan jawaban dan menggerakan tangan)". (P2 ) 
"ya pernah lah, ya misalnya dari pengisian status di tengok juga kita kan kan disitu cara kinerja kita dinilai misalkan kita melakukan kesalahan kasi obat,atau askep nya salah pasti ada dikasi tau lah ka, ini bukan kek gini, jdi dikasi tau". (partisipan pendukung P1,P2)

"kalo arahan sih . misalnya kalo ada alat baru. Itu kita dibimbing penggunaan alat atau segala macam nya,kalo dari segi tindakan kek persalinan normal. Apa segala macam , karena disini kebetulan karena bidan rata-rata jadi udah pada mahir. Paling kalo ada tindakan yang agak susah atau kek mana baru di kasih tau (pandangan kearah peneliti)". (P3 )

"ee pengarahan biasa kadang kalo kita melakukan kesalahan ada langsung dikasih arahan, contoh kemaren kek ada kesalahan dalam pemberian obat gitu kan paling ya Cuma memberi teguran sama kepala ruangannya, diberi penjelasan kenapa bisa sampai salah itu aja ( mengangkat tangan saat berbicara)”. (P4 )

" ada ya ,kerja samalah dengan anggotanya sama-sama proses juga dalam mendiskusikan” (partisipan pendukung P3,P4)

"bimbingan ada kadang dikasi aaa dikasi tau, misalnya salah kasi obat, dikasi tau jangan lagi kek gini, jangan sampai salah lagi ngasih gitu

( pandangan ke arah penilti)”. (P5 )

" ada ada, kita diarahkan di kasih tau kita nya (menganggukkan kepala)"

"ya kalo ada yang baru atau giman akan hmm langsung ngadain rapat dan dijelaskan berdiskusi dan bertukar pendapat". (partisipan pendukung P5,P6)

" kalau ada perubahan diagnosa, nanti dijelaskan, diagnosa yang masuk lain diagnosa beberapa hari yang lewat beda diagnos nya iya mungkin itu aja,aaaa ia ada hhh biasa nya sih di nerstation, kalau ditempat pasien gak di diskusikan diluar ( menjelaskan sambil menggerakan tangan)". (P7 )

" oo ada disinikan ada jugak meeting yaa satu kali dalam sebulan memang ada, ia evaluasi semua dibicarakan, ada info info terbaru pelatihan-pelatihan semua juga dibicarakan (menjelaskan sambil memegang pulpen)". (P8) " ada kita di bimbing, di kasih tau jika ada yang baru dan kita eee dipantau juga oleh karunya". (partisipan pendukung P7,P8)

Kinerja

"ya pasti ada. Pengaruhnya pasti ada dengan kinerja bawahannya,ya kalo atasan care pasti bawahan lebih enak kerjanya. Kalo ada solusi atau masalah jadi cepat untuk mengungkapkan nya. Tapi kalo misalnya gak care gimana bawahannya mau ini kan, kerjapun jadi tidak nyaman (menganggukan kepala sambil menegaskan jawaban)". (P1) 
"Sangat berpengaruh, Kalo pemimpinnya mengayomi bawahan nya,merangkul bawahan nya anggota pun akan semangat kan dan pemimpin tidak hanya merintah tapi juga menguasi apa yang di perintahkan, termotivasi la anggotanya (menganggukkan kepala sambil memegang sisi meja)". (P2 )

"pengaruh lah kalau ibu inikan ngomong nya lebih santai dia orangnya lebih santai tidak menekan, ada karu kami yang menekan, jadi kerja tu gak semangat, ada kesalahan sedikit ya kami langsung di panggil menghadap ke dia, padahal itu masalah spele, yaaa setiap orang beda beda,jadi kalau kek gitu anggota nya jadi malas lah kan". (partisipan pendukung P1,P2) "ada ya, menjadi lebih baikla. Ya setidaknya kita lebih maju la. Yang dulunya belum banyak kemajuan sekarang dah maju la. Udah banyak dapat ilmu baru karena kan kita di kasih tau (menggerakan kepala ke bawah)". (P3 )

" kalo secara logika sih sebenarnya pasti ada, eeh karna kadang pemimpin yang keras pemimpin yang cuek gitu kan pemimpin yang biasa-biasa aja pasti ada pengaruhnya heeh (menggerakan tangan dan menolehkan kepala)".(P4 )

"ada pengaruhnya ya kadang kalo karunya gak pedulikan ,bisa aja perawatnya berfikir untuk apa bekerja bagus sedangkan karunya aja gak bagus, kan ada juga gitu he, kalo Cuma diam aja duduk aja datang masuk ruangan itu kan ada juga mempengaruhinya. Tapi kalo karunya rajin kan kita juga ikut rajin, kan kinerja yang bagus juga untuk karu, katim, perawat pelaksana, ya saling berhubungan kalo di atas gak baik ya di bawah juga gak baik. Semua berhubungan dengan komunikasi. Gituu".(partisipan pendukung P3,P4)

“iyaa berpengaruuh, jadi semangat lah kita ni kan bekerja, karna karu kita care-care nyaa kita jadi nya enak kan, kalau banyak tekanan tentu kita tertekan juga kan kerjanya (menganggukkan kepala)". (P5)

"ya sangat berpengaruh lah, ya kalau karu nya seperti itu kinerja kita kan makin menurun kan coba kepala ruangan nya terbuka sama kita kan, kita bisa meningkatkan kinerja kita kan (menganggukkan dan menggerakan tangan) ". (P6 )

"iya heeh berpengaruh, kalo ada apa-apa juga berpengaruh kalo karunya care perawat kan terbuka dan semangat kerjanya".

(partisipan pendukung P5,P6)

"ada ada pengaruh nya, kalau misalnya pemimpinnya menunjukkan yang baik kepada pasien ya kita ikut baik jugak, kalau dia gak peduli dengan pasien ya kita juga jadi malas juga kok yang di atas gak pduli gitu jadi yag dibawah juga malas juga (menganggukkan kepala)". (P7 ) "ya pasti pengaruh lah kalo kepala ruangannya memimpinnya bagus pasti kebawahnya juga bagus (menganggukkan kepala)". (P8 ) 
"ada pasti ada, gaya kepemimpinan yang menekan anggotanya akan membuat suasana ruangan menjadi tidak nyaman tapi jika karunya menerapkan gaya kepemimpinan fleksibel terkadang disitu yang membuat kita lebih dekat hubungannya dan kerja pun lebih efisien dan nyanan. Seperti itu".

(partisipan pendukung P7,P8)

\section{PEMBAHASAN}

\section{Kepemimpinan}

Berdasarkan ungkapan partisipan bahwa kepemimpinan itu adalah seseorang yang bisa memimpin dan mengayomi serta mengarahkan anggotanya. Tidak hanya sekedar memimpin tetapi pemimpin itu rela berkorban waktu, tenaga dan pikiran serta saling bekerja sama untuk mencapai tujuan bersama. Hal ini sesuai dengan teori yang di kemukakan oleh Kuntoro (2010), Kepemimpinan adalah suatu seni dan proses untuk mempengaruhi dan mengarahkan orang lain supaya mereka memiliki motivasi untuk mencapai tujuan yang hendak dicapai dalam situasi tertentu. Kepemimpinan juga merupakan suatu inti kegiatan kelompok, hasil timbal balik dan hubungan antar pribadi, dan sebuah kepribadian yang memiliki pengaruh tertentu terhadap orang lain untuk berfikir, bersikap, dan berprilaku dalam merumuskan citacita kelompok atau organisasi dalam situasi yang sangat khusus.

Uraian di atas juga di dukung teori yang dikemukakan oleh Thoha (2012), yang menyatakan Suatu organisasi akan berhasil atau bahkan gagal sebagian besar di tentukan oleh kepemimpinan. Suatu ungkapan mulia yang mengatakan bahwa pemimpinlah yang bertanggung jawab atas kegagalan pelaksanaan suatu pekerjaan, merupakan ungkapan yang mendudukan posisi pemimpin dalam suatu organisasi pada posisi yang terpenting. Seorang pemimpin apapun wujudnya, dimana pun letaknya akan selalu mempunyai beban untuk mempertanggung jawabkan kepemimpinannya. Pemimpin seperti ini lebih banyak bekerja dibandingkan berbicara, lebih banyak memberikan contoh-contoh baik dalam kehidupan nya dibandingkan berbicara besar tanpa bukti, dan lebih banyak berorientasi pada bawahan dan kepentingan umum dibandingkan dari orientasi dan kepentingan diri sendiri.

Uraian di atas sesuai dengan penelitian yang dilakukan yayan hardiansah (2013), yang menyatakan kepemimpinan merupakan kemampuan untuk mempengaruhi dan menggerakan sekelompok orang bukan dengan paksaan untuk mencapai tujuan tertentu. kemampuan yang dimilikinya, pemimpin dapat memotivasi dan mendorong karyawannya untuk melakukan pekerjaan sesuai dengan apa yang di arahkannya agar mencapai tingkat kerja yang diharapkan sehingga tujuan tujuan dan keberhasilan organisasi dapat dicapai. 
Dalam hal ini, dibutuhkan kemampuan pemimpin dalam mempengaruhi bawahannya agar mau dan suka bekerja, tidak semata-mata menerima perintah dari atasan, tetapi tergerak hatinya untuk menyelesaikan tugasnya dengan kesadaran sendiri. Seringkali terjadi hambatan dalam pelaksanaannya, karena yang digerakkan adalah manusia yang mempunyai keinginan pribadi, sikap, dan perilaku yang khusus. Oleh sebab itu, kepemimpinan yang dapat meningkatkan motivasi dan sikap kerja bawahan menjadi hal yang penting (Suarli S \& Yanyan B, 2010).

Berdasarkan pengamatan yang dilakukan peneliti ditemukan bahwa kepala ruangan membina hubungan baik dengan anggotanya dengan cara mengayomi dan merangkul anggota sehingga terciptanya kerja sama untuk mencapai tujuan bersama.

Berdasarkan uraian di atas peneliti berasumsi bahwa pemimpin mempunyai peranan penting terhadap anggotanya dalam menggerakkan serta bertanggung jawab atas anggotanya sehingga terjalin kerja sama yang erat untuk mencapai tujuan bersama.

Gaya kepemimpinan

Berdasarkan ungkapan partisipan bahwa gaya kepemimpinan yang diterapkan kepala ruangan di ruangan rawat inap rumah sakit petala bumi adalah demokrasi. Pemimpin melibatkan anggotanya dalam berdiskusi dan memberikan kesempatan kepada anggota untuk mengemukakan pendapat. Hal ini sesuai dengan hasil penelitian Maryanto (2013), menyatakan bahwa berdasarkan gaya kepemimpinan yang paling baik adalah demokrasi, gaya demokrasi merupakan kepemimpinan yang bersedia memberikan bimbingan yang efisien kepada bawahannya, bersedia mendengarkan pendapat, ide, saran dan kritikan dari bawahannya. Kepemimpinan yang demokrasi ini memiliki kekuatan pada partisipasi aktif pada anggota kelompok.

Sedangkan menurut Thoha (2012), gaya kepemimpinan yang efektif atau baik adalah gaya kepemimpinan situasional sehingga dapat meningkatkan motivasi kerja dari bawahannya. Hal ini didukung oleh penelitian yang dilakukan oleh Agus (2014), yang menyatakan bahwa pemimpin yang baik adalah pemimpin yang dapat memadukan antara gaya kepemimpinan otoriter dengan demokrasi. Bawahan memerlukan pengawasan yang ketat dengan memberikan intruksi dalam situasi yang darurat dan juga sangat perlu untuk dilibatkan dalam pengambilan keputusan. Situasi yang demikian dapat meningkatkan kedisiplinan dan motivasi kerja anggota.

Gaya kepemimpinan yang diterapkan dalam suatu rumah sakit dapat membantu menciptakan efektifitas kerja yang positif bagi anggota. Adanya gaya kepemimpinan yang sesuai dengan situasi dan kondisi organisasi maka anggota akan lebih semangat dalam menjalankan tugas dan kewajiban serta harapan terpenuhinya kebutuhan. 
Uraian di atas didukung dalam teori yang dikemukakan oleh Suarli S dan Yanyan B (2009), gaya kepemimpinan dibagi menjadi tiga bagian, yaitu kepemimpinan otokratik (autocratic leadership), kepemimpinan partisipatif (participative leadership), dan kepemimpinan free reign (free reign leadership). Seorang pemimpin yang menerapkan gaya kepemimpinan otokratik (autocratic) menganggap bahwa semua kewajiban untuk mengambil keputusan menjalankan tindakan, mengarahkan, memberikan motivasi dan mengawasi bawahannya berpusat ditangannya. Pemimpin seperti ini merasa bahwa hanya pempinanlah yang berkompeten untuk memutuskan dan menganggap bahwa bawahannya tidak mampu untuk mengarahkan diri mereka sendiri. Kepemimpinan partisipatif artinya pemimpin tidak mendeklarasikan wewenangnya untuk membuat keputusan akhir dan untuk memberikan pengarahan tertentu kepada staf/bawahannya. Akan tetapi, ia mencari berbagai pendapat dan pemikiran dari para bawahannya mengenai keputusan yang akan diambil. Pemimpin dengan gaya partisipatif akan secara serius mendengarkan dan menilai pemikiran para bawahannya dan menerima sumbangan pemikiran mereka, sejauh pemikiran tersebut bisa dipraktikkan. Pemimpin seperti itu akan mendorong kemampuan mengambil keputusan dari para staf/bawahannya. Selain itu, pemimpin juga mendorong staf agar meningkatkan kemampuan mengendalikan diri dan menerima tanggung jawab yang lebih luas. Meskipun, tentu saja wewenang terakhir dalam pengambilan keputusan ada pada pemimpin. Kepemimpinan free reign artinya pemimpin mendelegasikann wewenang untuk mengambil keputusan kepada para bawahan dengan agak lengkap. Di sini pemimpin menyerahkan tanggung jawab atas pelaksanaan pekerjaan tersebut kepada para staf/bawahan. Dalam hal ini, pemimpin menginginkan agar para staf/bawahannya dapat mengendalikan diri mereka masing-masing dalam menyelesaikan tugas tersebut.

Berdasarkan hasil pengamatan yang dilakukan peneliti bahwa kepala ruangan menerapkan gaya kepemimpinan situasional. Pada situasi tertentu kepala ruangan mengambil kebijakan sendiri tanpa melibatkan anggota dan pada situasi tertentu kepala ruangan perlu melibat kan anggota dalam menentukan kebijakan. Saat kepala ruangan menerapkan gaya kepemimpinan demokrasi karena pentingnya kerja sama dalam menyelesaikan masalah yang membutuhkan pemikiran bersama. Kepala ruangan mengambil keputusan sendiri pada saat membutuhkan tindakan yang cepat dan tepat dalam hal menangani pasien. Sehingga kepala ruangan dapat menjalankan fungsinya sesuai dengan tanggung jawabnya.

Berdasarkan uraian di atas peneliti berasumsi bahwa perilaku kepemimpinan akan tercermin dari gaya kepemimpinannya yang muncul pada saat memimpin bawahannya. Dalam mempengaruhi kinerja bawahannya diperlukan gaya kepemimpinan yang efektif.

Supervisi kepala ruangan 
Berdasarkan ungkapan partisipan bahwa supervisi kepala ruangan salah satunya adalah memberikan pengarahan dan bimbingan kepada anggota. jika anggota melakukan kesalahan akan di beri penjelasan agar kesalahan tidak terulang lagi serta saling berbagi ilmu baru. Hal ini sesuai dengan hasil penelitian Zulfikhar (2016), Kepala ruangan sebagai pemimpin perlu melakukan pembinaan atau pengarahan kepada perawat pelaksana dan pengembangan motivasi, inisiatif dan keterampilan agar dapat melaksanakan tugasnya dengan baik, dalam hal ini pemimpin harus mampu memberitahu, menjelaskan, bekerja sama dan memonitor perilaku perawat sesuai dengan situasi yang ada untuk dapat meningkatkan motivasi kerja perawat sehingga dapat melaksanakan tugasnya dengan baik dan sesuai dengan tujuan yang telah disepakati.

Berdasarkan uraian di atas peneliti berasumsi bahwa tanggung jawab sangat dibutuhkan bagi seorang kepala ruangan dalam memberikan pengarahan dan bimbingan kepada perawat pelakasana agar lebih terampil dalam proses asuhan keperawatan sehingga pelayanan yang diberikan oleh perawat lebih maksimal.

Kinerja

Berdasarkan ungkapan partisipan bahwa gaya kepemimpinan kepala ruangan akan berpengaruh terhadap kinerja perawat. Jika kepala ruangan lebih care akan membuat anggota lebih bersemangat dalam bekerja. Jika gaya kepemimpinan kepala ruangan tidak disukai olah anggota maka akan menurunkan semangat anggota.

Menurut Nursalam (2015), kinerja merupakan hasil kerja yang dapat dicapai oleh seseorang atau sekelompok orang dalam suatu organisasi sesuai wewenang dan tanggung jawab masing-masing dalam rangka upaya mencapai tujuan organisasi secara legal, tidak melanggar hukum dan sesuai moral maupun etika. Faktor yang mempengaruhi kinerja yaitu faktor organisasi yang meliputi sumber daya, kepemimpinan, imbalan, struktur, desain kerja. Faktor individu yang meliputi kemampuan dan keahlian (fisik dan mental), latar belakang (keluarga, tingkat sosial, pengalaman). Faktor psikologi yang meliputi persepsi, sikap, kepribadian, motivasi.

Berdasarkan hasil pengamatan yang dilakukan oleh peneliti bahwa anggota terlihat bersemangat dan merasa nyaman dalam menyelesaikan tugas dan tanggung jawabnya di karenakan gaya kepemimpinan yang diterapkan kepala ruangan disukai oleh anggota. Kepala ruangan yang lebih care membuat anggota lebih terbuka dan lebih aktif menjalankan aktivitas di ruangan.

\section{KESIMPULAN}


Persepsi perawat pelaksana tentang kepemimpinan yaitu seseorang yang bisa memimpin dan mengayomi serta mengarahkan anggotanya. Tidak hanya sekedar memimpin tetapi pemimpin itu rela berkorban waktu, tenaga dan pikiran serta saling bekerja sama untuk mencapai tujuan bersama. Gaya kepemimpinan yang di terapkan kepala ruangan di 4 ruang rawat inap rumah sakit petala bumi adalah demokrasi. Pemimpin yang melibatkan anggotanya dalam berdiskusi dan memberikan kesempatan kepada anggota untuk mengemukakan pendapat. Supervisi kepala ruangan salah satunya adalah memberikan pengarahan dan bimbingan kepada anggota. Pada penelitian ini perawat pelasana mempersepsikan bahwa gaya kepemimpinan kepala ruangan akan berpengaruh terhadap kinerja perawat. Dengan gaya kepemimpinan yang baik akan membuat anggota merasa nyaman di dalam ruangan dan meningkatkan semangat anggota sehingga kerja pun lebih efisien.

\section{DAFTAR PUSTAKA}

Kuntoro, A. (2010). Buku Ajar Manajemen Keperawatan. Yogyakarta: Nuha Medika.

Maryanto (2013). Hubungan gaya kepemimpinan kepala ruang dengan kepuasan kerja perawat di Rumah Sakit Swasta di Demak. Jurnal Managemen Keperawatan, 1(2). Diperoleh dari http://download.portalgaruda.org/article.php?article=137454\&val=5086. Nursalam. (2015). Manajemen Keperawatan : aplikasi dalam praktik keperawatan professional, edisi 5. Jakarta : Salemba Medika.

Rustiyanto, E. (2010). Statistik Rumah Sakit Untuk Pengambilan Keputusan. Yogyakarta: Graha IImu.

Saragih, N. (2011). Hubungan Program preceptorship dan karakteristik perawat dengan proses adaptasi perawat baru di PKSC, RSB, dan RSPI. Diperoleh dari

http://lib.ui.ac.id/file?file=digital/20282012-T\%20Nurmaida\%20Saragih.pdf

Suarli, S \& Yanyan, B. (2009). Manajemen keperawatan dengan pendekatan praktis : Jakarta: Erlangga.

Suyanto. (2008). Mengenal kepemimpinan dan manajemen keperawatan di rumah sakit. Jogjakarta : Mitra Cendikia Press

Thoha, M. (2012). Kepemimpinan dalam manajemen. Jakarta : Rajawali Pers.

Torang, S. (2013). Organisasi dan manajemen (Prilaku, struktur, budaya dan perubahan organisasi). Bandung : Alfabeta. 
Zulfikar. (2016) Hubungan antara gaya kepemimpinan kepala ruang dengan motivasi kerja perawat pelaksana di rumah sakit islam Surakarta. Skripsi terpublikasi. Diperoleh dari http://eprints.ums.ac.id/44684/1/NASKAH\%20PUBLIKASI.pdf. 